\title{
MULTIPLE UNIT, VOLTAGE SPEED CONTROL FOR TRUNK LINE SERVICE.
}

\author{
BY H. WARD LEONARD.
}

A description of a single phase, high tension, alternating current system for operating trunk line railways. Conversion takes place on each locomotive and substations are eliminated. Illustrated.

In February, 1894, I read a paper before this Institutb describing a system which I considered applicable to the operation of a trunk line electric railway. The essential features of this system were:

1st. The generation and transmission of a high tension single phase alternating current, the power houses being placed as far apart as the insulation of an alternating current transmission would permit.

$2 d$. The entire elimination of sub-stations.

3d. A transformation of the energy upon the locomotive so as to secure a voltage speed control for the electric motors, thereby obtaining smooth acceleration and efficient control of the locomotive at any desired speed and in either direction.

At that time there were no engineers, so far as I know, who agreed with me that these features were essential for the operation of a trunk line railway by electric motors.

In the recent past, however, many prominent engineers both abroad and in this country have declared themselves in favor of these essential features, and I therefore feel warranted in describing an improvement upon the system I originally proposed, by which I can secure the important and now well understood advantages of a multiple control of any desired number of locomotive units.

Fig. 1 illustrates diagramatically one form of my multiple unit, voltage speed control as applied to two locomotive units for trunk line service.

The current is genorated in the form of a single-phase alternat- 
ing current at as high an e.m.f. as is practicable to-day, say 20,000 volts. A moving contact leads the single phase alternating current upon the locomotive. If desired, static transformers can be placed at suitable points along the line of the railway which will reduce the initial e.m.f. to any desired lower e.m.f. upon the contact conductor.

In many instances it may be desirable to place upon the locomotive a transformer ' $\mathrm{s}^{\prime}$ for reducing the tension of the alternating current led to the synchronous motor $\mathrm{A}^{1}$.

A single phase synchronous motor on the locomotive receives this alternating current and is driven by it continuously at a practieally constant speed; the current after passing through the motor, being led to ground through a moving contact. This

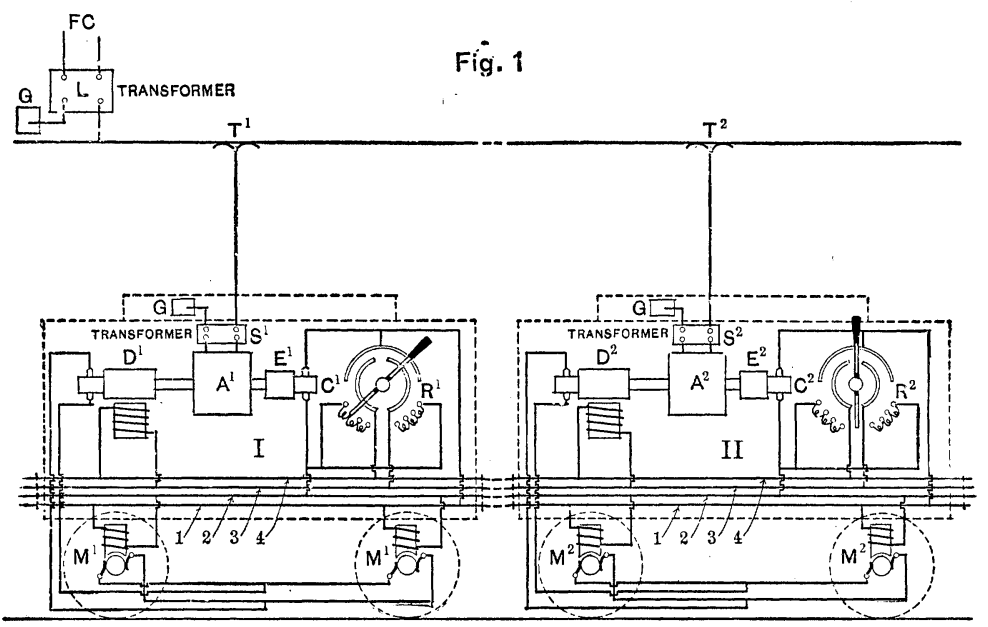

single phase motor $\mathrm{A}^{1}$ drives continually a small exciter $\mathrm{E}^{1}$ and also a large continuous current dynamo $D^{1}$ whose field is separately excited by the exciter $\mathrm{E}^{1}$ and has in its field circuit a reversing field rheostat $\mathrm{R}^{1}$. The armatures of the propelling motors are connected in multiple directly across the terminals of the armature of the dynamo $\mathrm{D}^{1}$. The field magnets of the propelling motors $\mathrm{M}^{1}$ are separately and constantly excited by the exciter $\mathrm{E}^{1}$.

By manipulating the reversing field rheostat $R^{\mathbf{1}}$, the current through the armatures of the motors $\mathrm{M}^{1}$ necessary to obtain the required tractive effort, can be obtained at any desired voltage from the lowest voltage to the full speed voltage, and in either direction. 
A perfectly smooth and rapid acceleration can thus be obtained with minimum energy from the source of supply.

The simultaneous multiple control of the several locomotive units is obtained by means of the four small wires $1,2,3,4$, which are lead along the train.

In Fig. 1 the operator is supposed to be upon the locomotive I. The exciter $\mathrm{E}^{1}$, which is producing a constant e.m.f., has its terminals connected to the wires 1 and 2 . Across these wires 1 and 2 are connected the field windings of all of the propelling motors on the two locomotives, so that they are all constantly and fully excited.

The wires 3 and 4 are also supplied by a current from the exciter $E^{1}$, but the reversing field rheostat $R^{1}$ is in the path of this current. The fields of the two dynamos $\mathrm{D}^{1}$ and $\mathrm{D}^{2}$ are connected in multiple across thése wires 3 and 4 which extend a1ong the train.

It will be evident that by manipulating the reversing field rheostat $\mathrm{R}$ the operator can vary, simultaneously and similarly the field exciting currents supplied to $\mathrm{D}^{1}$ and $\mathrm{D}^{2}$ and that therefore he can cause the voltage of these two dynamos to vary in exact unison from 0 to the maximum voltage in either sense. Thus, the operator can cause the two locomotives to start, accelerate, run at full speed, retard, and reverse in perfect unison, always dividing the load perfectly under these various conditions.

By placing the controller $\mathrm{R}^{1}$ in its open position and going to the other locomotives, the operator can similarly control the two locomotives simultaneously hy means of the controller $\mathrm{R}^{2}$.

By the use of this system I expect to be able to secure the following advantageous features:

1st. The haulage over existing roadbeds, grades, bridges, etc., of very much heavier trains than can be hauled by any steam locomotive.

2d. A material reduction in the cost of maintenance of the locomotives as compared with steam locomotives.

3d. A material saving in the maintenance of the road bed because of the absence of hammer blow, shouldering, rocking and skidding.

4th. A material increase in the weight of the train which could be hauled around a certain curve by a locomotive having a certain weight on drivers.

5th A material increase in the load which could be started 
upon a certain grade by a locomotive having a certain weight on drivers.

6th. A material reduction in the dead load necessarily hauled by a steam locomotive, represented by the part of the steam locomotive and tender not on drivers.

7 th. A very large increase in the number of trains of given weight and speed which could be operated from a given power house compared with the series parallel or cascade systems. Or, to state this another way: a very much higher rate of acceleraticn with the same maximum output from the power house, the same conductors, the same weight per train and the same watt hours per ton mile, than is possible with the series, parallel or cascade systems.

8th. As each locomotive unit can be equipped with any desired number of driving axles and any desired number of locomotives can be operated under multiple control, the amount of power which can be applied to a single train and controlled by a single operator is practically unlimited.

9th. Fifty per cent. of the energy now wasted on friction brakes can be saved in the form of useful electrical energy restored to the system.

10th. The first cost of equipment will be very much less than that of any system, for equivalent service, which involves the use of sub-stations.

$1 i_{\text {th. }}$ The cost of haulage per ton mile will be greatly reduced as compared with steam locomotives, especially because of the large increase in the weight of the train which can be hauled.

12th. Difficulties due to electrolysis would be reduced to a minimum. 